\title{
Robotics in Construction: Opportunities and Challenges
}

\author{
Akshay Kamath, Rahul Kumar Sharma
}

\begin{abstract}
Building and construction is one of the major industries around the world. Construction industry is labour-intensive and is conducted in dangerous situations; therefore the importance of construction robotics has grown rapidly. Applications and activities of robotics and automation in this industry started in the early 90 s aiming to optimize equipment operations, improve safety, enhance perception of workspace and furthermore, ensure quality environment for building occupants. The main goal of this paper is to convince building designers and managers to incorporate robotic systems when managing modern buildings. This paper studies recent applications for robots and automation in the construction industry and sets opportunities and challenges through a new framework for better planning and control of construction equipment operation.
\end{abstract}

Keywords: buildings, Automation, safety, management, opportunities

\section{INTRODUCTION}

Construction marketplace generally in countries numbers to 10--20 percent of their GNP, which makes it the sector that is employing. Construction job is labor - intensive and can be run in both conditions substances affect and the task material[1]. Robots have been employed to support employees. This process shows flexible approach, and an autonomous, adaptive, easy. Building robotics was a research field within the building industry [2]. The paper's purpose would be to persuade managers and construction designers to add systems when structures that are managing to conserve energy and boost effectiveness. The goals of the paper comprise, among the many others: 1)) Assessing current programs and jobs to get utilizing automation and robots Within the Building Business, two) Putting chances and Challenges confronting using robots within the development business, 3) Predicting fluctuations in structure industry caused by robot utilization (and 4) Putting frameworks for far superior preparation and constraint of development functions. The demand for automating is warranted the processes and also, software and engineering such as robotics in development marketplace are all identified. Programs for selecting/assembling robotics technique and best automatic according to activities in structure will work are discovered.

Revised Version Manuscript Received on 10 September, 2019. AkshayKamath, Civil Engineering, Noida Institute of Engineering and Technology, Greater Noida, Uttar Pradesh, India.

(Email: : research.paper@niet.co.in)

Rahul Kumar Sharma, Computer Science Engineering, Noida Institute of Engineering and Technology, Greater Noida, Uttar Pradesh, India.

(Email: : research.paper@niet.co.in)

\section{FUTURE OF BUILDING INDUSTRY}

Improvements in construction production have become necessary and essential as the next few years can observe a huge migration. Experts imply in 2015,55 percent of the whole world's people will dwell within the metropolitan regions [3]. The part of personal computer technology software in development varies. Artificial intelligence (AI) offers a fresh software for treating large scale and intricate subject issues.Meet customers and Construction creation is supposed to enhance operation. It is hard to maintain sight but also the objective and the graphic. Developments of structure process consequence of transforming conditions and circumstances which contribute to enhanced functionality to the customer[4].

\section{AUTOMATION}

In construction: The job good results from your job direction's perspective is accomplished while the job is done with all the best attainable price tag, the maximum high good quality, zero injuries, etc.. To put it differently, good results signifies attracting every one of their job operation indexes (PPI)- like as price, schedule, quality, protection, labor productivity, substances waste or consumption, etc., to an optimal price. Making use of robotics and automation will be retrieved by the view of increasing construction project's operation to function as the surroundings and both the customer [5]. Automation and robotics methods within the construction sector can Attain the next benefits: Security for the two employees and the general public through deploying and growing machinery to get more both tasks that are dangerous.

Caliber with increased precision than that given by the employee. Hence the Employees are relieved from labor places that were uneasy improving labor surroundings as guide function is significantly decreased to some minimal Removing fretting about Dirt and sound recording functions like planning, cleaning or elimination of surfacesproductivity and work effectiveness with lower prices[6]. The last 2 years have seen that a hunt among investigators to find tactics to present robotics. Back in Japan manipulators had been utilized to structure employees as supporters. This method permits the robot to function as less complicated and more sovereign, requiring just detection talents. As stated by the particular approach, the individual anatomy controls the task's regions, and also the robot can be utilized to enlarge the bodily limitations. Procedures, of the operation that was 
autonomous, may be accommodated in an assortment of construction tasks [7].As progress of the building procedure are the endeavor into their near future advancements insure worker security anatomy engineering, design plans, improvement tracking, and production details that are spread. Numerous strategies of incorporating the utilization of robots and humans within structure areas have been introduced[8].

In constructing roads: Likewise cracks seal and could fill jogging across the street, such as between also the shoulder and lanes. The motorist remote-controls the procedure, and also fractures can be filled by the system. When compared with a sealing surgery could have a crew daily to perform 2 or two kilometers per hour Robots can also be currently assisting remove debris and litter, just the other labor intensive operation [9].These actions linked to works could be gained.- Development of the platform to get air while operator finishes final fragile regions of the task .- A masonry robot which pre-plans its activities. During this undertaking, including a world-wide placement detector adjusts deviations of their robot software Center Point (TCP) because of inactive deflection of this manipulator structure [10].

Window glass panel or mounting adjusting with a robot using servo motor and pneumatic actuator. Even the robot mechanics that is hybrid-type includes a variety of precision and workspace, and it is composed of sequential and port [11].- welding whilst the robot also describes the nozzle and monitors that the seam whilst welding it [12].- Prefabrication of all GRC components fabricating such as for example spraying panels, additionally rationalization and optimization which include panels' transport and storage [13].indistinguishable, Straightforward, robotic robots build structures utilizing modules. Collars are able of any advice processing, so letting them talk range info and also convey. This communicating allows buildings to become built with a few neighborhood robot behaviors [11].- Attaching ceramic tile walls utilizing an engineered robot that manipulates or lifts the tile while it is attached by an employee upon the wall. In experimentation, the suggested structure robot lifts the tile (5 kilogram) and moves through the ring trail. The supposed slipping control is more efficient to get a pneumatic cylinder controller (determine 5) [12].- Renewal of facades with apparatus mind, a manned stage or some other lifting apparatus: a Method consisting of 3 elements, along with a vacuum cleaner. The use is that old coat with the brush or the elimination of rough-cast. The vacuum "absorbs" the contaminants from the surface, passing them by its pits into some receptacle. The atmosphere Is Subsequently filtered, and also the reject split Between designated

\section{SECURITY OF BUILDINGS}

Waiting for safety purposes following the commissioning of estate or properties must guarantee a quality natural setting. In case robots can do the surveillance occupation, the efficacy might be improved, leading to safety of their direction team and economies of work. What's more, in the event the robot may recover controls against the construction administration system by means of a neighborhood area network (LAN), additionally reductions in labor might be accomplished regarding Firstline malfunction presence by individual direction to staff [13]. The evolution of the protection system at which in fact the security helmet demanded in building web sites for the majority of employees can be employed to adapt communicating tools and placement. The location and I do of every employee are obtained and delivered into your channel, in which in fact the info is more contrasted to a database. As stated by this, both machines and workers' places are understood in, each hazard and instant cases could possibly be understood and prevented [20].

\section{CHALLENGES\& RESULTS}

Automation in construction's participation may be that the evolution of a comprehensive investigation of advantages and expenses related to a program. It is essential to test success during the financial and technical feasibility. The feasibility will be dependent on an appraisal of steps required to do exactly that the work undertaking that was given, also from investigation of their need for procedure tracking and laser management. The feasibility, that will be regarded as the crucial component on the industry achievements of their approaches that were projected, is dependent on the investigation of their costs and advantages. Technologically ambitious feature and Procedure of practice building software include [14]:

Performance at work website surroundings that is barbarous or even Un-defined and at times ailments for example: Complicated climatic Problems

Experience of Dirt

Calibration in Connection with surroundings Adjustment to altering surface states Complexity of their functioning surroundings A few changes at the essence of this do the job procedure as opposed to the conventional function procedure.- Profession "Sense-and-Act" performance for cellular building robots to successfully Do delicate or accurate jobs - analysis of Various Kinds of items in surroundings states that are organic - Interactivity Amongst end-tools and detectors

In contrast would be technologically demanding and can be grown in to the building niche throughout first phases of integration. Even the "perception - and-Act" course of action are likely to eradicate the demand for elevated precision when placing the robot in its work station, true that conserves time and contributes to larger economical feasibility of this body. Some investigators experimented with raise the freedom number of bots by simply enabling them to navigate and independently to map their environment. Though construction websites are distinguished by incorrect geometries, a lot of challenges, etc., the navigation and mapping systems could possibly be accommodated to it[15]. Navigation systems are all predicted to address one of your problems at achieving outcomes and triumph. Programmers and Scientists of robots also have tried to resolve the issue of altering the robot by simply acquiring self-positioning procedures along with mapping. The robot afterward navigates in 1 work station to another [16].Forsberg et al. indicated a plastering robot which employs a rotational laserlight to quantify and then map its own environment (openings and walls). The mapping info had been interpreted

Published By:

Blue Eyes Intelligence Engineering

\& Sciences Publication

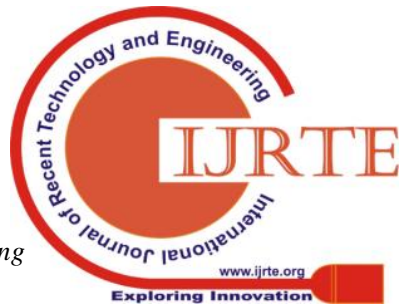


into a strategy, which may be offered for the operator to get developments. The system relied on methods and has been assumed to attract the robot into over \pm inch $\mathrm{cm}$ of its own workstation [13].Beliveau clarified an orientation platform to get in-door automatic guided vehicles (AGVs), together with about 3 laser transmitters precisely positioned to the ground in points that were known. Tests on this particular system showed the prevalence of the path contrary to the course was $\pm 10-\mathrm{cm}[16]$. Rosenfeld and shohet analyzed the precision attainable by mapping of structure surroundings. It had been discovered when robot placement has been accurate (orientation and position mistakes of $0.2^{\circ}$ and $3 \mathrm{~cm}$ (respectively), the attainable precision of indoor air mapping was $--5 \mathrm{~cm}$ ). The amount of precision is enough for responsibilities which don't need connection with all the treated part (e.g. spraying). But, activities which demand precise setting of aspects (e.g. block planting and tiling) calls for mapping precision of two $--3 \mathrm{~mm}$, in addition to using well-controlled end-tools [17].

\section{CONCLUSION}

At last it is concluded that Robots are involved in Construction surgeries to keep up action also to reduce threats achieving basic protection and management.Automated structure can be grown to add: technology, layout, upkeep of planned and existing arrangements.- Many re-search works indicate autonomous method because of its structure operation. Even the "Sense-and-Act" could become a real possibility within the evolution of advanced autonomous approaches such as construction software.Real-time preparation is used in activities that need the robot to compete with environments and doubts.- Efforts Ought to Be compensated to persuade specialists at construction automation to Enhance the Attribute of and construction direction to Start Looking in the Prospect of incorporating robotics Services for modern buildings that are intelligent.

All suggestions for robotizing or construction around the construction site must get generated with means of a composite of brand new varieties fresh layouts and substances that satisfy certain requirements. Nevertheless, Lots of issues in building technology May Not be completely addressed optimization and computation.

Together with intellect Activities like Decision-making, analysis and generalization to get multi-objectives, there may be much better comprehension of the development technology issue.

\section{REFERENCE}

1 A. Elliott, "Automated mobilities: From weaponized drones to killer bots," J. Sociol., vol. 55, no. 1, pp. 20-36, Mar. 2019.

2 U. Egertsdotter, I. Ahmad, and D. Clapham, "Automation and Scale Up of Somatic Embryogenesis for Commercial Plant Production, With Emphasis on Conifers," Front. Plant Sci., vol. 10, Feb. 2019.

3 E. D. Ona Simbana, P. Sanchez-Herrera Baeza, A. Jardon Huete, and C. Balaguer, "Review of Automated Systems for Upper Limbs Functional Assessment in Neurorehabilitation," IEEE ACCESS, vol. 7, pp. 32352-32367, 2019.
4 L. Liu, "Occupational therapy in the Fourth Industrial Revolution," Can. J. Occup. Ther. Can. D ERGOTHERAPIE, vol. 85, no. 4, pp. 272-283, Oct. 2018.

5 L. He and J. Schupp, "Sensing and Automation in Pruning of Apple Trees: A Review," AGRONOMY-BASEL, vol. 8, no. 10, Oct. 2018.

6 J. H. Britt et al., "Invited review: Learning from the future-A vision for dairy farms and cows in 2067," J. Dairy Sci., vol. 101, no. 5, pp. 3722-3741, May 2018.

7 M. Pan, T. Linner, W. Pan, H. Cheng, and T. Bock, "A framework of indicators for assessing construction automation and robotics in the sustainability context," J. Clean. Prod., vol. 182, pp. 82-95, May 2018.

8 J. A. Hashem, M. Pryor, S. Landsberger, J. Hunter, and D. R. Janecky, "Automating High-Precision X-Ray and Neutron Imaging Applications With Robotics," IEEE Trans. Autom. Sci. Eng., vol. 15, no. 2, pp. 663-674, Apr. 2018.

9 F. L. Siena, B. Byrom, P. Watts, and P. Breedon, "Utilising the Intel RealSense Camera for Measuring Health Outcomes in Clinical Research," J. Med. Syst., vol. 42, no. 3, Mar. 2018.

10 I. R. Kawaminami-Garcia, O. M. Rodriguez-Elias, S. R. Meneces-Mendoza, and M. J. Velazquez-Mendoza, "ROKA: A software development methodology for industrial automation.," in 2018 6TH INTERNATIONAL CONFERENCE IN SOFTWARE ENGINEERING RESEARCH AND INNOVATION (CONISOFT 2018), 2018, pp. 42-49.

11 V. Lohchab, M. Kumar, G. Suryan, V. Gautam, and R. K. Das, "A Review of IoT based Smart Farm Monitoring," in PROCEEDINGS OF THE 2018 SECOND INTERNATIONAL CONFERENCE ON INVENTIVE COMMUNICATION AND COMPUTATIONAL TECHNOLOGIES (ICICCT), 2018, pp. 1620-1625.

12 R. Y. M. Li and D. P. L. Ng, "Wearable Robotics, Industrial Robots and Construction Worker's Safety and Health," in ADVANCES IN HUMAN FACTORS IN ROBOTS AND UNMANNED SYSTEMS, 2018, vol. 595, pp. 31-36.

13 N. Unnikrishnan, K. Hull, and E. Nicolson, "A REVIEW OF CHALLENGES IN INTEGRATING ROBOT AND MOTION CONTROL INTO A SINGLE SYSTEM," in PROCEEDINGS OF THE ASME INTERNATIONAL MECHANICAL ENGINEERING CONGRESS AND EXPOSITION, 2017 VOL 14, 2018.

14 M. Z. Mahmoud, M. Aslam, M. Alsaadi, M. A. Fagiri, and B. Alonazi, "Evolution of Robot-assisted ultrasound-guided breast biopsy systems," $J$. Radiat. Res. Appl. Sci., vol. 11, no. 1, pp. 89-97, Jan. 2018. 
15 B. Gorissen, D. Reynaerts, S. Konishi, K. Yoshida, J.-W. Kim, and M. De Volder, "Elastic Inflatable Actuators for Soft Robotic Applications," Adv. Mater., vol. 29, no. 43, Nov. 2017.

16 H. Zakeri, F. M. Nejad, and A. Fahimifar, "Image Based Techniques for Crack Detection, Classification and Quantification in Asphalt Pavement: A Review," Arch. Comput. METHODS Eng., vol. 24, no. 4, pp. 935-977, Nov. 2017. 